\title{
Short-term Rainfall Forecasts using the Regional Spectral Model (RSM): Performance and Verification
}

\author{
W.K. WONG, H. LAM, C.C. LAM AND C.K. CHOW \\ Hong Kong Observatory, Hong Kong
}

\begin{abstract}
Heavy rain during spring and summer in Hong Kong often causes considerable disruptions in social and economical activities. The Hong Kong Observatory (HKO) is running a high resolution Regional Spectral Model (RSM) to improve short-term rainfall forecasts. For operational use at the HKO, if rainfall forecasts over model grid points covering Hong Kong territory exceed certain threshold values, model rainfall alerts will be issued to the forecasters.

The RSM system, which is adapted from the Japan Meteorological Agency (JMA), implements physical initialization to incorporate hourly rainfall amount based on (1): rainfall analysis using radar reflectivity against raingauge data and (2): cloud cover and cloud top temperature from Geostationary Meteorological Satellite. Numerical simulations for past heavy rainstorm cases using $20-\mathrm{km}$ horizontal resolution reveal that the model can give a significant improvement over the 60-km resolution in prediction of rainfall in the initial hours of forecasts.

In this paper, we will discuss the model performance in rainfall forecasts for April - June 1999. Objective verification of rainfall forecasts using scores like Probability of Detection (POD) and False Alarm Ratio (FAR) will be presented. Model performance will also be illustrated using rainstorm cases. Rainfall amount, spatial distribution and its temporal trend during forecast hours will be compared with actual observations.
\end{abstract}

\section{Introduction}

Hong Kong Observatory (HKO) is operating a high-resolution numerical weather prediction (NWP) model to facilitate rainstorm forecasts. During spring and summer, persistent and heavy rain associated with the low-pressure surface trough, monsoon or tropical cyclones often lead to social and economical disruptions. If heavy rain over a certain amount has been fallen or is expected to fall generally over Hong Kong, the Observatory will issue rainstorm signal to alert the public about the occurrence of heavy rain. The rainstorm signal system is composed of three levels of warning according to the amount of rainfall: the AMBER, RED and BLACK with their respective threshold of 30, 50 and 70 millimetres of rainfall in an hour. If a rainstorm system develops rapidly, typically in 0-3 hours in the vicinity of Hong Kong, forecasters can base on the synoptic scenario depicted from rapidly update automatic weather station observations and sequences of radar or satellite imageries to issue the warning to the public. In longer term (more than 3 hours), the NWP products will become important for forecasters' reference to predict the occurrence of heavy rain. If a considerable amount of surface rainfall is predicted in model output, forecasters will be alerted to monitor closely the local or synoptic development during that period.

The direct model output data for predicting evolution of meteorological elements and surface rainfall are usually displayed as sets of graphics ready for forecasters. Moreover, to speed up the model interpretation process, an automatic weather forecast scheme is also devised to produce a text-based forecast for the Hong Kong area summarizing all key features and spatial distribution of model data prediction. For instance, if certain elements in model 
predictions exceed their warning thresholds, thunderstorm warning or rainstorm warnings can then be issued. In this connection, the automatic forecast scheme can provide a baseline for forecasters to add on their experience to produce a better forecast.

The purpose of this paper is to discuss the performance of Regional Spectral Model (RSM) in rainfall forecasts for April - June 1999. The model configurations will be outlined in Section 2 and the automatic forecast scheme for model rainstorm warning signal will also be briefly described. The score of rainfall forecast in April to June using RSM of 60-km horizontal resolution will be given in Section 3. Some rainstorm cases will be highlighted to illustrate the improvement of rainfall prediction due to increase in model spatial resolution. A summary will be given in Section 4 .

It is noted that in mentioning the time for a rainfall event, it is often referred to the local time (HKT) which is 8 hours ahead of the universal time (UTC).

\section{Model Description and Automatic Weather Forecast Scheme}

HKO began to run a $60-\mathrm{km}$ version of RSM in 1998 to simulate synoptic to mesoscale phenomena and to provide guidance for heavy rain forecast. The development of RSM in HKO was based on the Regional Spectral Model of the Japan Meteorological Agency (JMA). The model details are described in NPD/JMA (1997). It provides 3-hourly forecasts up to a total of 48-hours twice a day. The prediction output from the previous run provides the initial condition for the current forecast. The boundary conditions are obtained from the Global Spectral Model (GSM) of JMA. Though the model simulated well on synoptic feature for evolution of atmospheric and thermodynamic fields in some rainstorm cases, the mesoscale features usually could not be clearly depicted and the rainfall amount was less than actual, especially when the heavy rain event happened in the first few forecast hours. To improve model performance, a higher resolution version, with $20-\mathrm{km}$ spatial grid size, was then developed. This higher resolution version uses radar derived rainfall data for physical initialization to better initialize the moisture field so as to alleviate the model spin-up problem for forecasting rainfall. It was illustrated in a simulation of rainstorm case (Lam and Wong, 1999) that this higher resolution model can improve the rainfall forecast within the first 12 hours.

The 20-km version has been on trial run since April 1999. Due to limitation of computer resource, the model is configured to provide 12 hour forecast at hourly intervals. It is nested inside the $60-\mathrm{km}$ RSM with its domain enlarged to get the boundary conditions. Figure 1 shows the domain for the two models. The 20-km RSM runs eight times a day while the 60-km RSM runs four times. The Nowcasting Division of the Observatory routinely prepares rainfall analysis data and the data are used in hourly "pre-runs" during the period prior to initial 
hours in both models. In particular, the rainfall data are inserted three times in 20-km RSM while only once for 60-km model (Figure 2).

The direct model output will be processed through an automatic scheme to generate a text-based forecast for Hong Kong. Forecast elements over grids in Hong Kong region are used (Figure 3). The scheme produces forecast information on wind, state of sky, precipitation type, visibility, temperature, relative humidity and warnings for thunderstorms and rainstorms. For example, hourly rainfall predicted by $20-\mathrm{km}$ RSM over 25 grids around Hong Kong are used to calculate the rainstorm signal according to the following criteria:

\begin{tabular}{|l|c|c|c|}
\hline Warning & AMBER & RED & BLACK \\
\hline Hourly rainfall (RF) & $10 \mathrm{~mm} \leq \mathrm{RF}<16 \mathrm{~mm}$ & $16 \mathrm{~mm} \leq \mathrm{RF}<22 \mathrm{~mm}$ & $\mathrm{RF} \geq 22 \mathrm{~mm}$ \\
\hline
\end{tabular}

Table 1 Criteria for Rainstorm Warning Forecast

These criteria are derived from calibration of model output with actual rainfall observations.

\section{Rainfall Forecast Performance and Verification}

The 20-km RSM has been semi-operational since April 1999. During April and June 1999, there were several rainstorm events that brought considerable amount of rain over Hong Kong. There were also two tropical cyclones affecting Hong Kong during the period. Typhoon Leo (9902) necessitated the hoisting of No. 8 Northeast Gale or Storm Signal on 2 May and that was the earliest No. 8 signal in a year since 1946. Typhoon Maggie (9903) hit Hong Kong directly on 7 June and the Increasing Gale or Storm Signal No. 9 was hoisted during the early hours on that day. Performance of rainfall forecast during the tropical cyclone period is highly affected by the accuracy of forecast track of the tropical cyclone. Asymmetric typhoon bogus is used routinely in the model for better track forecast. The forecast track of Typhoon Leo using 60-km RSM will be discussed to illustrate certain capability of the model to forecast the track for tropical cyclones.

In verifying rainfall forecast by $60-\mathrm{km}$ RSM, rainfall amount forecasted at $\mathrm{HKO}$ grid point will be compared with actual records at HKO. The actual total rainfall on a day is taken from the amount of 24-hour rainfall recorded since mid-night. The DAY $1(\mathrm{D}+1)$ forecast rainfall is the total amount at HKO grid during 2300 HKT (1500 UTC) on the same analysis date to the same hour on the following day. According to rainfall verification scheme in HKO, the rain events are classified in five categories as tabulated below:

\begin{tabular}{|l|c|c|c|c|c|}
\hline Type & No rain & Light & Moderate & Heavy & Very heavy \\
\hline Daily rainfall amount $(\mathrm{mm})$ & 0 & $<10$ & $10-25$ & $25-50$ & $50-100$ \\
\hline
\end{tabular}

Table 2. Classification of daily rainfall amount in verifying $60-\mathrm{km}$ RSM rainfall forecast. 
If the forecast score is calculated from the number of correct forecasts within one adjacent category over the total number of samples, the rainfall forecast scores based on 0000 UTC and 1200 UTC analyses in these three months is summarized in the following Table 3. Some of the rainstorm cases that are not predicted correctly will be discussed in below sections.

\begin{tabular}{|l|l|l|l|}
\hline Score / \% & April & May & June \\
\hline 0000 UTC & 83.3 & 93.5 & 90.0 \\
\hline 1200 UTC & 86.2 & 93.5 & 90.0 \\
\hline
\end{tabular}

Table 3 DAY 1 Rainfall Forecast Score for 60-km RSM

\section{a. Rainfall Forecast Performance in April}

The first AMBER rainstorm event occurred on 12 April due to the influence of passage of a low-pressure trough. The AMBER rainstorm warning was hoisted from 0115 HKT to 0800 HKT. Rain was the heaviest over Hong Kong Island and eastern part of Lantau Island. However, both 0000 and 1200 UTC forecasts of the 60-km RSM on 11 April predicted the total rainfall in the following day was less than $10 \mathrm{~mm}$. In fact, the rainstorm system started developing significantly after mid-night. As the physical initialization process has to ingest the radar derived rainfall data for three hours prior to analysis time, the forecast by the $20-\mathrm{km}$ RSM with base time at 1500 UTC 11 April still did not predict much rainfall during this period. However, the rainfall predicted by $20-\mathrm{km}$ RSM run at 1800 UTC was much higher than previous run after the radar derived rainfall data were ingested (Figure 4).

During the last few days on April, the local weather was affected by the Typhoon Leo (9902). The rainfall predicted by the model during the period did not agreed well with the actual rainfall recorded. It is found that the forecast tracks were biased westward to the its best tracks, resulting in error of rainfall forecast. This bias error was gradually corrected when Leo was closer to Hong Kong. In particular, based on the forecast with initial time at 0000 UTC on 1 May (Figure 5), the error in 24 hour and 36 hour forecast positions from the best-track positions were 70 and $68 \mathrm{~km}$ respectively. The DAY 1 forecast rainfall was about 4 $\mathrm{mm}$ at $\mathrm{HKO}$ grid while the maximum value among the 9 model grid points for warnings was about $11 \mathrm{~mm}$. In comparison, the actual HKO rainfall recorded on 2 May was $9.6 \mathrm{~mm}$. The northwest turning of track for Typhoon Leo on 1 May was examined through various set-up of model simulation in Lam et.al. (1999). It was concluded that the success of the RSM in predicting the northwest turning was attributed to the use of asymmetric bogussing profile in the analysis and the fact that the forecast weakening of vortex strength of Typhoon Leo. 


\section{b. Rainfall Forecast Performance in May}

An AMBER rainstorm warning signal was hoisted during 0440 - 1345 HKT on 19 May as a result of the passage of a trough of low pressure over south China coast on 18 May. The largest amount of rainfall recorded at HKO was observed during $0400-0800$ HKT, with a maximum hourly rainfall of over $25 \mathrm{~mm}$ ending at $0500 \mathrm{HKT}$ recorded at HKO. Based on 0000 and 1200 UTC 60-km RSM runs on 18 May, the 3-hourly rainfall forecast ending at 0500 and $0800 \mathrm{HKT}$ did not exceed $5 \mathrm{~mm}$ (Figure 6).

The rainfall amount predicted by successive runs using 20-km RSM was closer to actual rainfall records. It is evident from the radar imageries (Figures 7) that the rainstorm was due to an intensifying band of echoes extended from western coast of Guangdong. With physical initialization using these data, the amount of rainfall forecast during early morning of 19 May were successively adjusted and exceeded the model AMBER rainstorm warning threshold (1-hr RF $>10 \mathrm{~mm}$ ). In forecast using analysis at $1500 \mathrm{UTC}$, the maximum rainfall among all 25 warning grid points at $0600 \mathrm{HKT}$ was $10.5 \mathrm{~mm}$. In the following run using analysis at 1800 UTC, the threshold was reached as early as $0500 \mathrm{HKT}$ and this was the time when the actual AMBER warning signal was issued to public (Figure 8). In this rain case, the series of rain forecasts and alert generated by the $20-\mathrm{km}$ model provided fore-warning of the rain in time to the forecasters.

\section{c. Rainfall Forecast Performance in June}

The direct hit of Typhoon Maggie (9903) resulted in over $60 \mathrm{~mm}$ of daily rainfall at HKO on 7 June. As the Typhoon Maggie was initially moving over the western North Pacific where it was close to the boundary region of RSM, the error of track forecast was quite substantial. When it took a northwest course and entered the South China Sea, the forecast tracks by $60-\mathrm{km}$ RSM were closer to the best track. Moreover, there was still some southward bias found in model runs on 6 June and this led to only moderate level of DAY 1 forecast rainfall that were less than actual records.

There was another heavy rainfall event on 21 June due to the influence of an unstable southerly airstream after the northward passage of low-pressure surface trough. AMBER rainstorm warning was sued by HKO between 0900 HKT and 1040 HKT. The 0000 UTC model run on 20 June predicted nil DAY 1 forecast rainfall while the 1200 UTC run forecasted a moderate level. The successive cycle runs for 20-km RSM out-performed the rainfall forecast by $60-\mathrm{km}$ RSM in this case. It is shown in Figure 9 that the rainfall predicted during the early hours on 21 June was gradually corrected by a successive update of 20-km RSM forecasts. 


\section{Discussion and Summary}

The performance of rainfall forecast during April to June 1999 using 60-km RSM is discussed. The rainfall forecast results for May is the best among the three months in this study. In predicting the moderate rainfall for DAY 1, the Probability of Detection (POD) is 0.5 and the False Alarm Ratio (FAR) is also 0.5. To forecast the heavy rain event on DAY 1, the POD can only be 0.33 while FAR reaches 0.67 .

It is the objective to improve the rainfall forecast performance by increasing the model resolution to $20 \mathrm{~km}$ and using the most current rainfall data from radar observations to initialize the model. With 3-hourly update cycle run, the model can analyze the rapid development of rainstorm system to improve the rainfall forecast. It is found that $20-\mathrm{km}$ RSM can simulate well the rain amount and its trends. In forecasting the AMBER rainstorm cases in April to June, the average POD is over 0.45 but the FAR is also very large (>0.9) due to the high sensitivity of model initial moisture content to the radar rainfall distribution. It is found that once the surface rainfall is generated through physical initialization in the model, the rainfall field can persist for several subsequent runs even after the rain event has been over, resulting in the large number of false alarms.

It is an on-going work to tune the model parameters to reduce the false alarms in the forecast of heavy rain events. The current thresholds for issuance of rainstorm and other warnings in the automatic forecast are based on previous rainstorm case studies. Therefore, these limits will be revised upon more rainstorm cases are analyzed.

Acknowledgements: The Regional Spectral Model (RSM) was adapted from Japan Meteorological Agency (JMA). We thank JMA for their support in the development of RSM in Hong Kong.

\section{REFERENCES}

Lam, C.C., and W.K. Wong, 1999: Numerical Simulation of the Heavy Rainstorm of 9 June 1998: the Impact of Physical Initialization, Third International Scientific Conference on the Global Energy and Water Cycle. 16-19 June 1999 Beijing China.

Lam, C.C., W.K.Wong and H. Lam, 1999: Forecasting the track of Typhoon Leo (9902) over the South China Sea, to be submitted.

Matsumura, T, I. Takano, K. Aonashi and T. Nitta, 1995: Improvement of spin-up of precipitation calculation with use of observed rainfall in the initialization scheme. J. Meteorol. Soc. Jpn., 73, 353-368.

NPD/JMA, 1997: Outline of the operational numerical weather prediction at Japan Meteorological Agency, March 1997. 
FIGURES

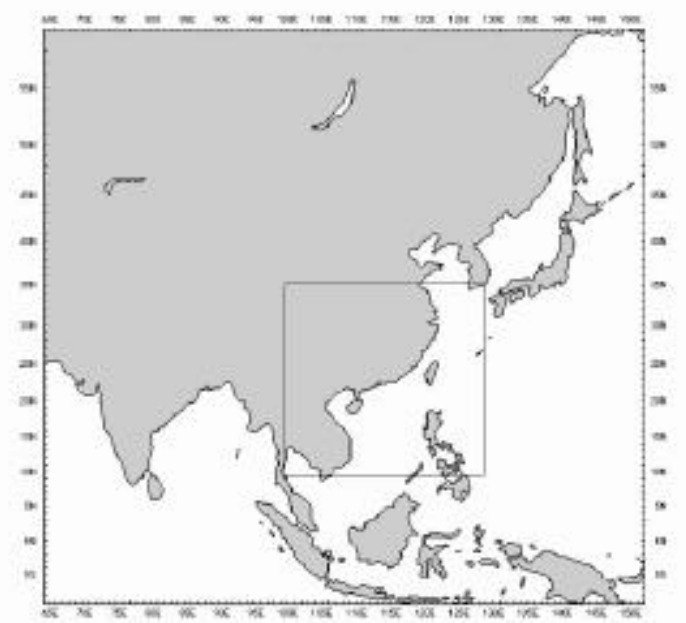

Figure 1. Domains for the 60-km RSM and the 20-km RSM (small square box).

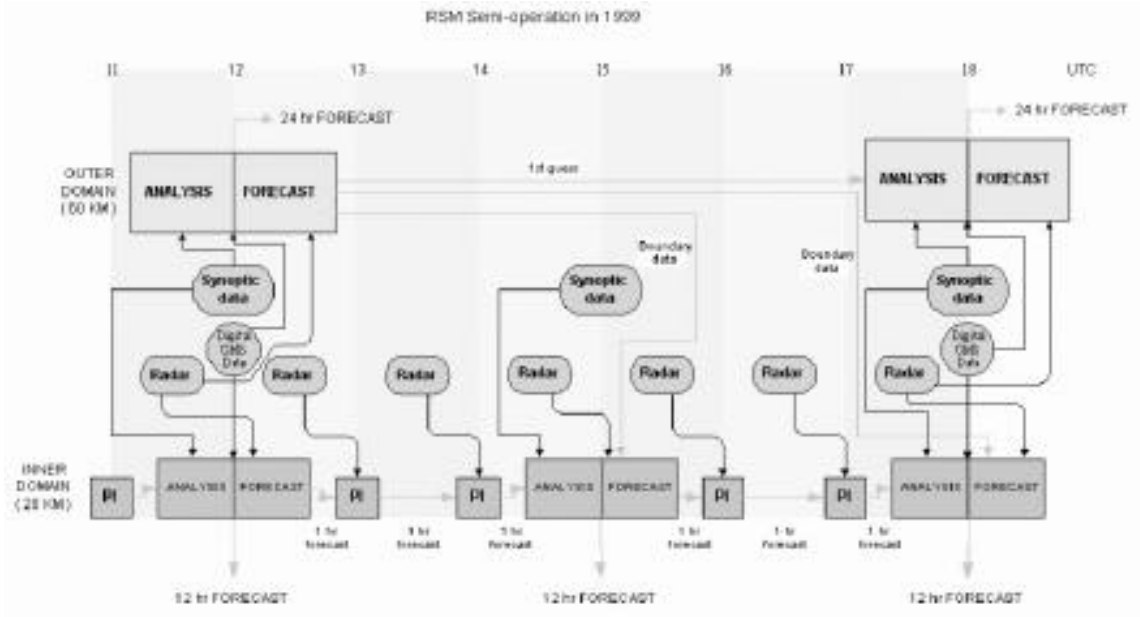

Figure 2. Data flow for the 60-km and 20-km RSM.
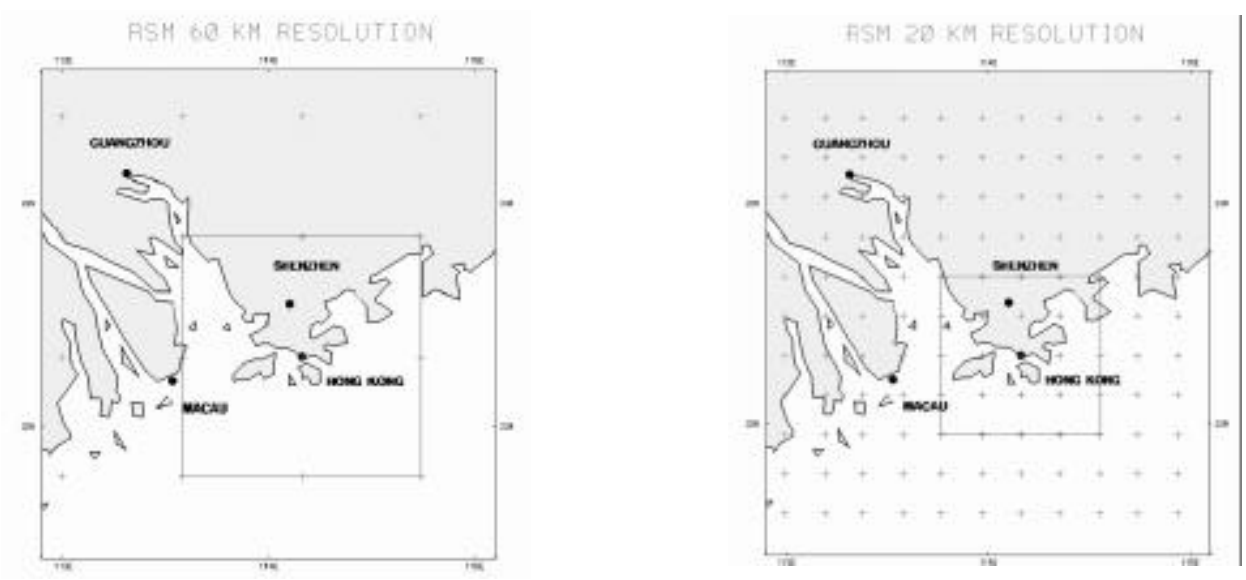

Figure 3a. Model grid data in the area Figure 3b. Model grid data (totally 25 indicated are used in generating warnings points) are used to produce warning for the 60-km RSM for HK. forecast for the 20-km RSM for HK. 


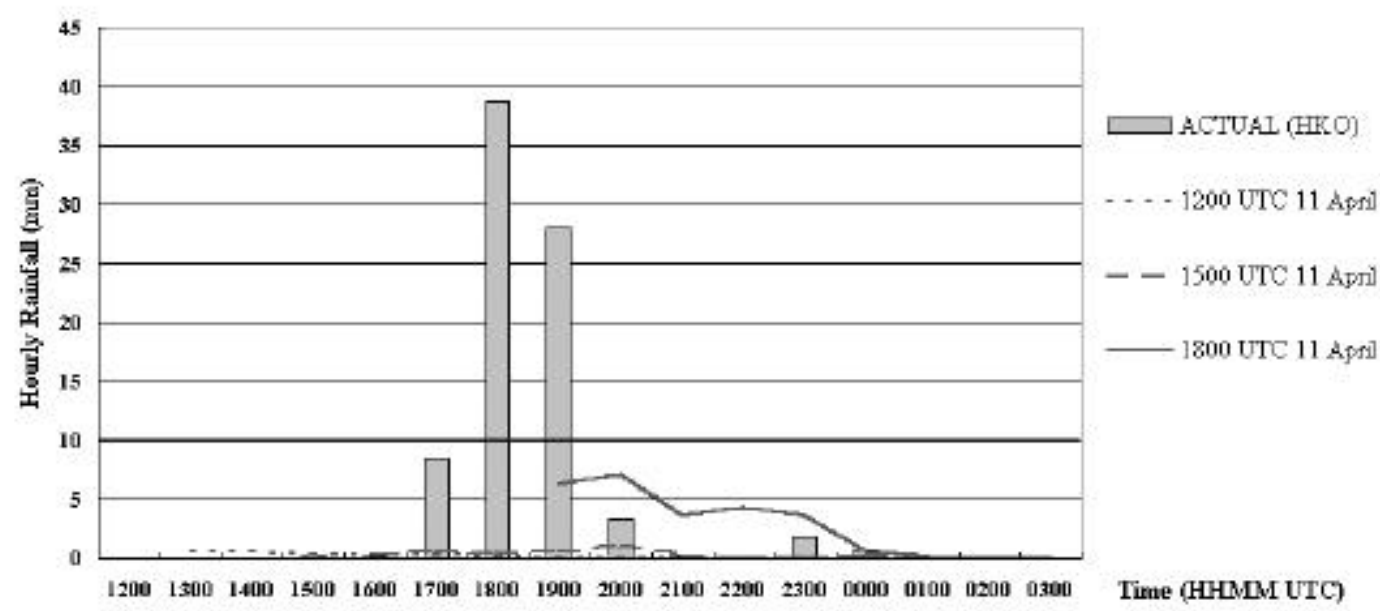

Figure 4. Comparison of actual HKO hourly rainfall against hourly forecast rainfall predicted by consecutive 20-km RSM run of initial time at 1200, 1500, 1800 UTC 11 April. The horizontal thick solid line shows the threshold to issue AMBER rainstorm warning by $20-\mathrm{km}$ RSM.

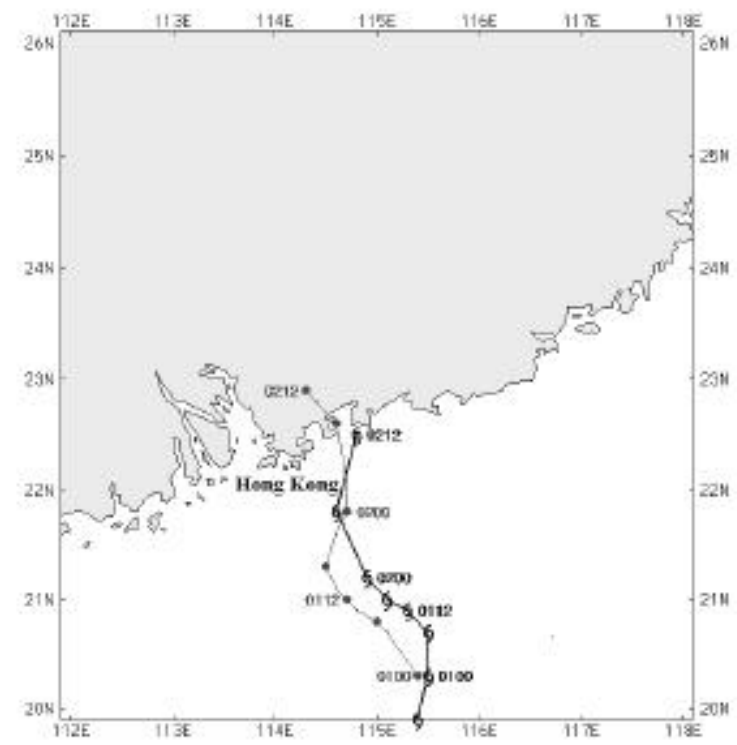

Figure 5. Forecast tracks against HKO best track (marks are spaced in 6-hour interval) for Typhoon Leo (9902) using 60-km RSM based on analysis at 0000 UTC 1 May, 1999. 


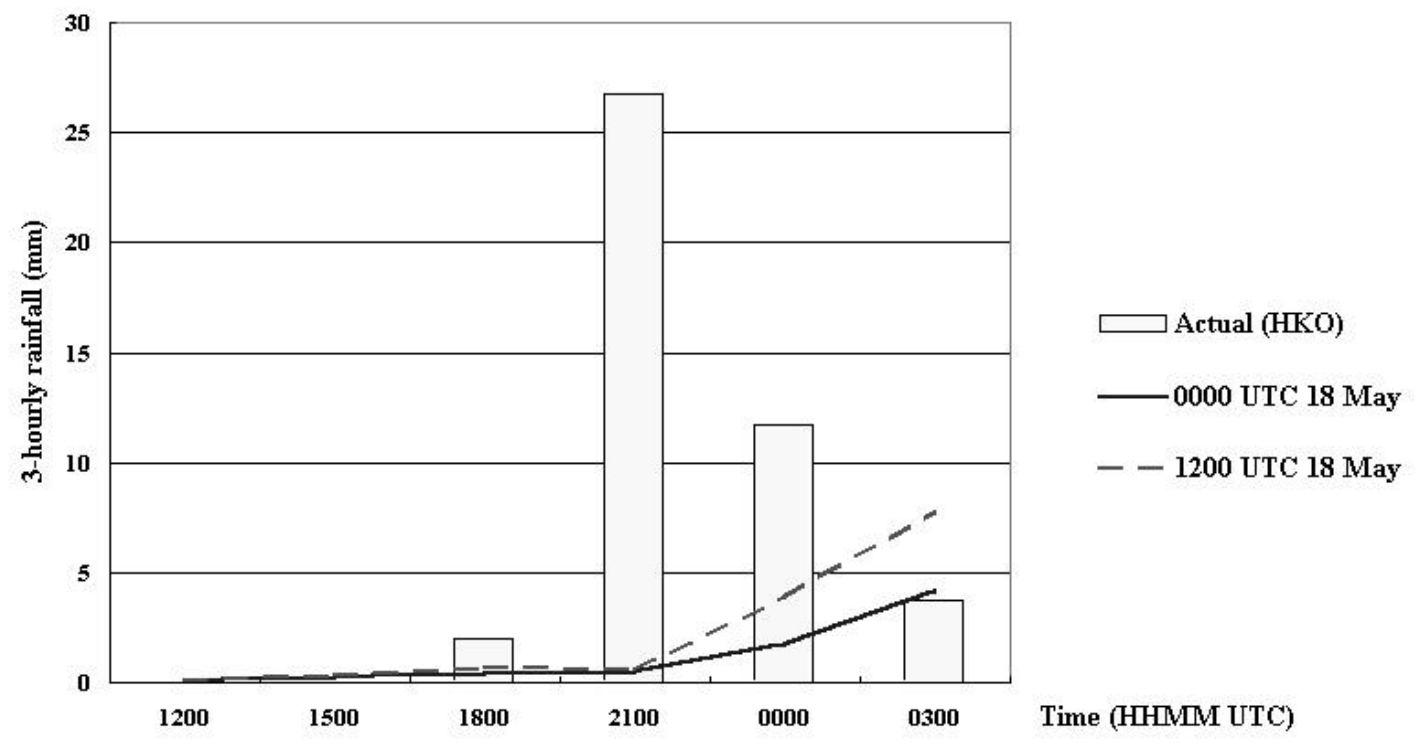

Figure 6. 3-hourly rainfall records at HKO against the 3-hourly forecast rainfall by 60-km RSM during 1200 UTC 18 May to 0300 UTC 19 May. The forecast rainfall data are based on model runs with initial hours at 0000 and 1200 UTC on 18 May.
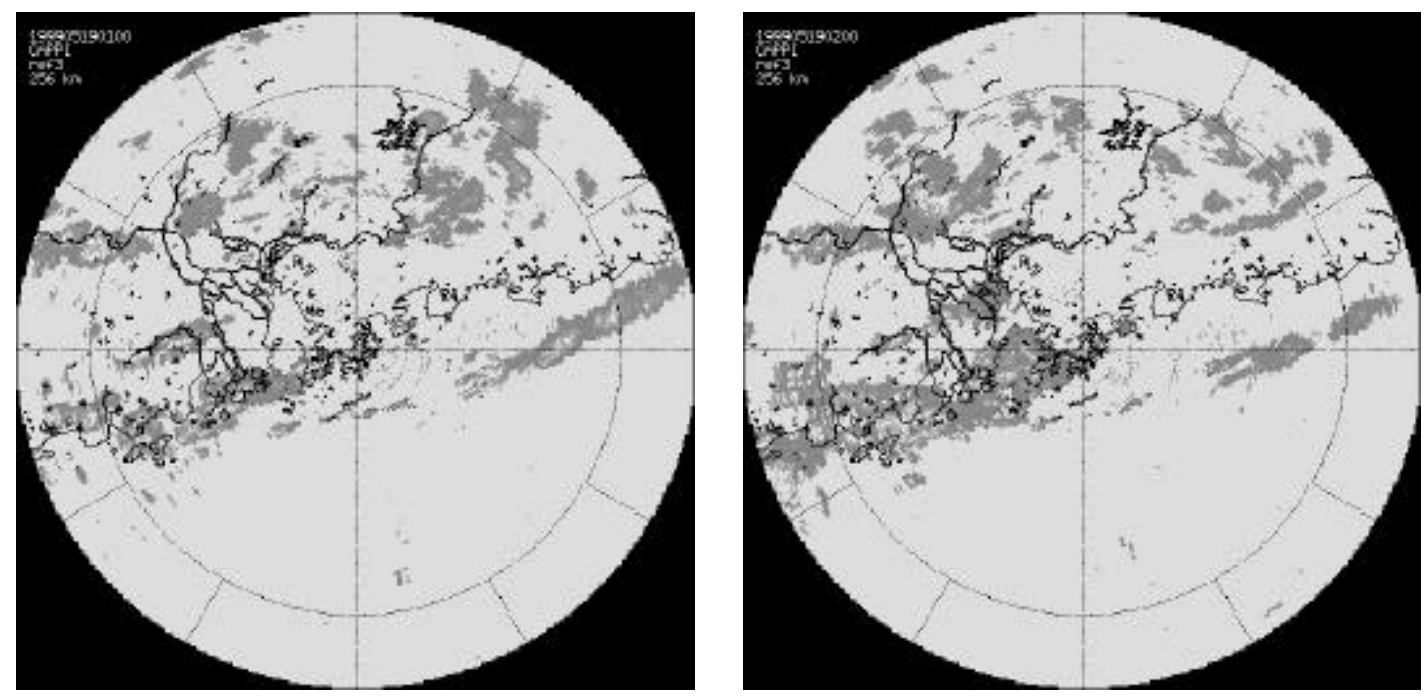

Figures 7. Hourly radar reflectivity CAPPI (at $3 \mathrm{~km}$ ) imageries during $0100-0200$ HKT on 19 May 1999. 


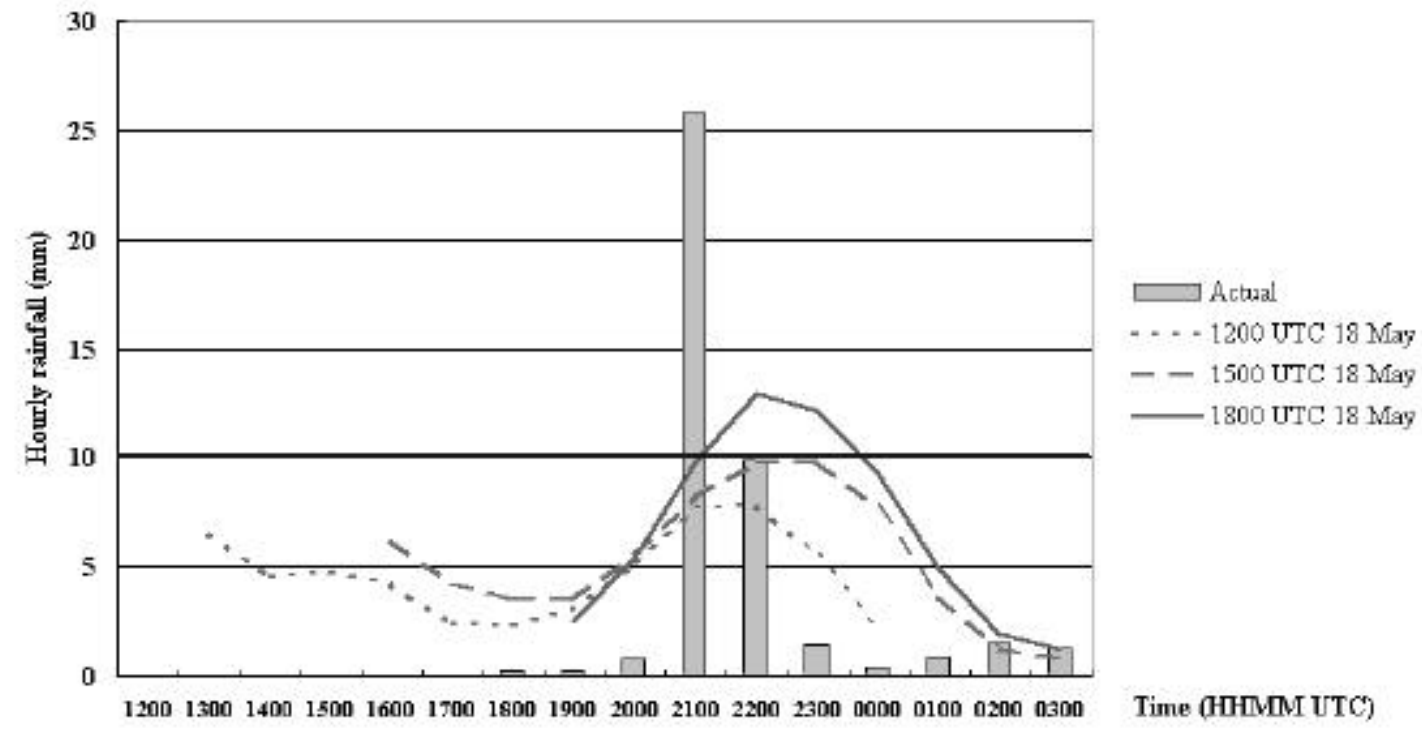

Figure 8. Hourly rainfall recorded at HKO against the forecast rainfall by $20-\mathrm{km}$ RSM run with initial time at 1200, 1500 and 1800 UTC on 18 May 1999.

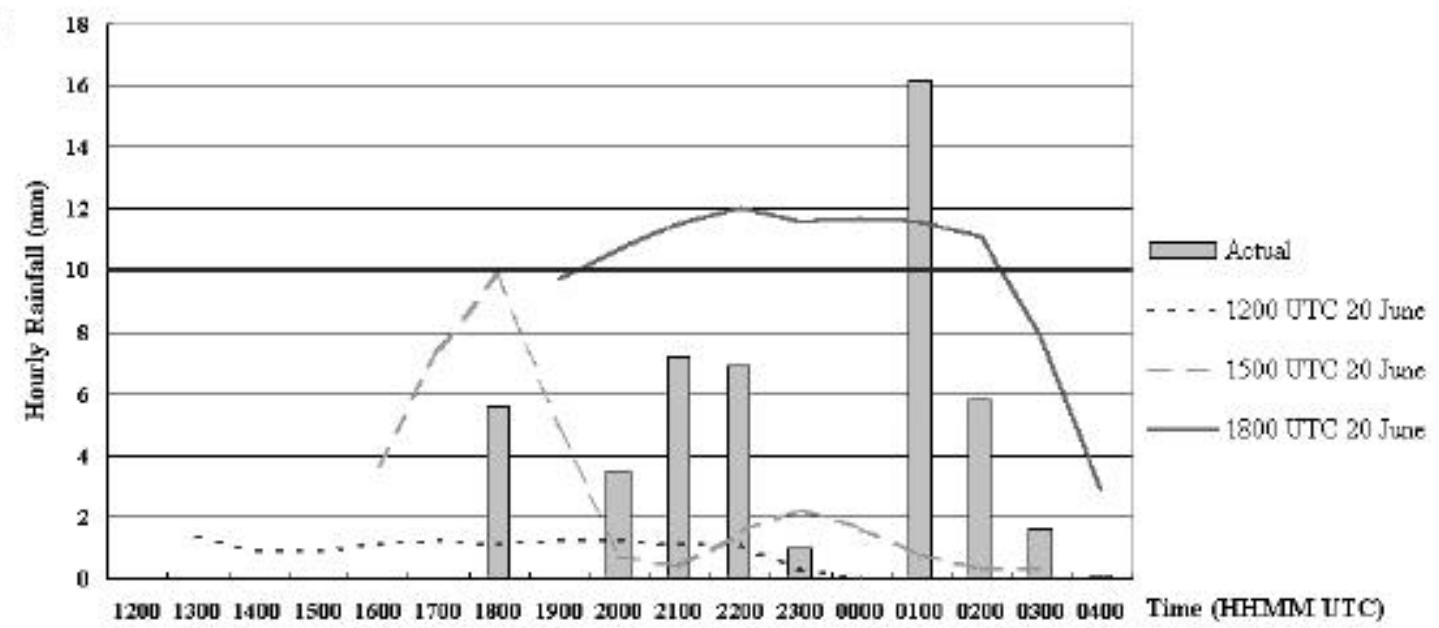

Figure 9. Hourly rainfall at $\mathrm{HKO}$ against the forecast rainfall by $20-\mathrm{km}$ RSM runs with initial time at 1200, 1500 and 1800 UTC on 20 June 1999. 